\title{
GESTÃO POR COMPETÊNCIAS E INDÚSTRIA 4.0 EM UMA EMPRESA ALAGOANA
}

\section{COMPETENCES MANAGEMENT AND INDUSTRY 4.0 IN AN ENTREPRISE FROM ALAGOAS}

Recebido em 30.09.2019 Aprovado em 10.12.2019

Avaliado pelo sistema double blind review DOI: https://doi.org/10.32888/cge.v7i2.38084

\section{Natanael Cicero de Lima Filho}

natanael.filho@,feac.ufal.br

Faculdade de Economia, Administração e Contabilidade/Universidade Federal de Alagoas - Maceió/Alagoas, 56 Brasil

\section{Milka Alves Correia Barbosa}

milka.correia@ffeac.ufal.br

Faculdade de Economia, Administração e Contabilidade/Universidade Federal de Alagoas - Maceió/Alagoas, Brasil

\section{Resumo}

A quarta revolução industrial exige das indústrias a modernização dos modelos de gestão de seus recursos organizacionais, inclusive os humanos, atendendo a necessidade de desenvolver pessoas de modo a aproveitar as suas competências. O objetivo deste estudo foi identificar a contribuição do modelo de gestão por competências para o desenvolvimento profissional dos funcionários de uma empresa que está na fase inicial de implantação dos conceitos da indústria 4.0. Através de entrevistas, foi feito um levantamento das competências dos colaboradores da organização escolhida, uma classificação das competências propostas por Silva, Kovaleski e Pagani (2019), foi verificado como a empresa usa a gestão por competências, a percepção dos funcionários sobre sua importância e foram levantados seis elementos que contribuem para o desenvolvimento profissional por meio da gestão por competências. A pesquisa possui natureza aplicada, exploratória e qualitativa. Foi constatado que o conhecimento técnico é a competência considerada mais importante, enquanto capacitações, treinamentos, cursos e formação, avaliações, desenvolvimento de profissionais multifuncionais e a elaboração de um plano de desenvolvimento individual foram tidos como elementos importantes para o desenvolvimento profissional.

Palavras-chave: Gestão por Competências. Competências. Desenvolvimento Profissional. Indústria 4.0.

\begin{abstract}
The fourth industrial revolution requires industries to modernize management models of their organizational resources, including human resources, given the need to develop people to take advantage of their skills. The objective of this study was to identify the contribution of the competency management model to the professional development of the employees of a company that is in the initial phase of the implementation of industry 4.0 concepts. Through interviews, a survey of the competencies of the employees of the chosen organization was made, a classification of the competences proposed by Silva, Kovaleski and Pagani (2019), six elements that contribute to professional development through competency management were raised. The research has an applied nature, exploratory and qualitative. It was found that technical knowledge is the most important competence, while qualifications, training, courses and formation, assessments, development of multifunctional professionals and the development of an individual development plan were considered as important elements for professional development.
\end{abstract}

Keywords: Competence Management. Skills. Professional development. Industry 4.0. 


\section{Introdução}

As mudanças no mercado de trabalho e a pressão por resultados influenciam as organizações a estarem constantemente melhorando sua estrutura, seus processos e a forma como as pessoas são geridas. A rápida evolução tecnológica e a intensificação da dinâmica de mercado resultaram na valorização do conhecimento como parte integrante do trabalhador, que permeia as diversas áreas organizacionais, contribuindo para o desenvolvimento da organização e passando a ser um diferencial competitivo nesse ambiente de constantes mudanças (CARBONE et al, 2009).

Esse cenário fortaleceu a necessidade de indivíduos polivalentes, capazes de executar múltiplas tarefas. Para Carbone et al (2009), as organizações perceberam que o investimento no desenvolvimento dos seus colaboradores, além de capacitá-los para ser multifuncionais, resultaria na melhoria da produção, e que consequentemente, só é possível por meio de um modelo de gestão de pessoas capaz de lidar com as singularidades dos trabalhadores e os direcionar para o objetivo almejado.

Desde a revolução industrial, os modelos de gestão de pessoas estão passando por modificações acerca da forma como os indivíduos são geridos e de como aproveitar o potencial humano no trabalho. No modelo taylorista-fordista de produção, designavam-se tarefas individuais predefinidas para os trabalhadores executarem de forma repetitiva e rotineira, incapacitando a ação dos mesmos em situações imprevistas, já que eles não eram preparados para lidarem com a incerteza, a não ser para aquela tarefa em que eram designados a executar (TREFF, 2016).

Os experimentos de Mayo na década de 20 foram o início de uma percepção mais humanizada do trabalhador, baseada no trabalho em grupo e em recompensas psicossociais. Na década de 40, o modo como as pessoas eram geridas foi burocratizado, assumindo um caráter mais rígido e exclusivamente voltado a atender as normas vigentes. Ainda em meados da década de 40, foi a partir dos estudos de Drucker e seguido pela abordagem neoclássica, que o colaborador passou a ser visto também como o trabalhador do conhecimento e não um funcionário passivo que segue normas organizacionais. A partir dos anos 50, com os trabalhos de Ludwig von Bertalanffy, responsável pelo surgimento da teoria geral de sistemas, foi que a organização passou a ser vista na perspectiva de um conjunto de áreas integradas e interdependentes, refletindo essa integração com as outras partes organizacionais na maneira de gerir as pessoas.

Um resgate histórico é feito por Ruzzarin e Simionovschi (2017) ao constatarem o surgimento da gestão de competências na década de 60 , por meio de um modelo de remuneração do tipo pay for skills (remuneração por habilidades). A partir nos anos 80 , com a difusão do conceito por outros setores econômicos, as empresas ficaram mais interessadas nesse sistema de remuneração, sendo também o início de muitos estudos sobre o que se entendia sobre gestão por competências.

A noção de competência surge como uma alternativa ao tradicional conceito de cargo. Na gestão baseada em cargos, o trabalhador é alocado para exercer um conjunto específico de tarefas e a organização move esforços para que, através de treinamentos e capacitações, ele esteja apto para tal, o que significa dizer que esse modelo é estruturado para formar profissionais especialistas. Enquanto na gestão por competências, o indivíduo é aproveitado nas atividades nas quais ele é capaz de desempenhar e os esforços são voltados para o desenvolvimento das competências que o indivíduo já possui e das que a organização precisa, ou seja, esse modelo preza por profissionais multitarefas. Há dois principais abordagens adotadas sobre o conceito de competência. O primeiro é utilizado desde as primeiras concepções, e consiste em competência como um conjunto de conhecimento, habilidades e atitudes. O segundo é o de competências individuais, definido como a entrega de valor agregado pelo indivíduo, que transforma o seu conhecimento, suas habilidades e suas atitudes em resultados e em contribuição para o conhecimento da organização (DUTRA, J., 2017). Por ser mais amplo e considerar a entrega de valor para a organização, esse último conceito será adotado para a definição de competências nessa investigação.

Entre os segmentos mais afetados pelas mudanças citadas nos modelos de gestão de pessoas, a indústria é um dos que mais precisam reagir a esse cenário, começando pela maneira que ela lida com o seu ativo mais importante: as pessoas, principalmente aquelas responsáveis pela administração da 
organização, visto que a gestão de pessoas não foi necessariamente acompanhada pelos departamentos administrativos, gerando uma lacuna entre a produção moderna e a administração convencional.

Em seu estudo de caso em uma indústria siderúrgica, Ceribeli e Almeida (2015) mostram que a implantação de práticas de gestão de pessoas alinhadas a gestão por competências facilita a transformação dos colaboradores em trabalhadores polivalentes. Portanto, espera-se que esse artigo possa contribuir tanto para a literatura, quanto para a aplicação do conceito de competências como entrega de valor na rotina de recursos humanos, em que uma empresa do setor industrial, ao direcionar esforços nesse sentido, possibilita o desenvolvimento profissional dos seus funcionários.

O investimento no desenvolvimento dos colaboradores se justifica com o advento da indústria 4.0, que vai além de tecnologias inovadoras, incluindo também a mudança no perfil dos trabalhadores, passando do trabalho manual para o intelectual e exigindo que as empresas invistam na formação dos funcionários (AIRES; MOREIA; FREIRE, 2017). Dessa forma, a aplicação dos conceitos e ferramentas da gestão de pessoas por competências se torna ainda mais necessária, principalmente nas empresas que estão em processo de transição para esse novo modelo de indústria, por considerar as habilidades, o conhecimento e a atitude do indivíduo e por estimular o desenvolvimento dele.

A partir de trabalhos de outros autores como Ceribeli et al. (2019) e de Carvalho, Stefano e Munck (2015), fica claro que há espaço para a discussão das práticas de gestão por competências aplicada nas organizações, visto que ainda há predominância de pesquisas exclusivamente teóricas sobre esse tema (CERIBELE; ALMEIDA, 2015).

Tomando como objeto de estudo uma indústria que está implantando o modelo de indústria 4.0, este trabalho se propõe a responder à pergunta: como a gestão por competências pode contribuir para o desenvolvimento profissional dos funcionários de uma empresa do setor industrial? Assim, o objetivo geral desse artigo é identificar a contribuição do modelo de gestão por competências para o desenvolvimento profissional dos funcionários de uma empresa que está na fase inicial de implantação dos conceitos da indústria 4.0. Especificamente, objetiva-se verificar como a empresa utiliza as competências na gestão de pessoas, fazer um levantamento das competências dos funcionários do setor administrativo e sugerir formas de contribuir para o desenvolvimento dos funcionários baseadas na gestão por competências.

\section{Gestão por Competências}

Datando quando surgiu o modelo de gestão de pessoas por competências, Gramigna (2017) informa que foi adotado inicialmente nos Estados Unidos, em meados de 1970, e posteriormente na Europa durante as décadas de 1980 e 1990. Chegou no Brasil aproximadamente em 1990, através de publicações e projetos de multinacionais. A autora define esse modelo como um conjunto de instrumentos, ferramentas, processos e metodologias focadas na integração das práticas de gestão estratégica de pessoas, apresentando melhores resultados para a organização.

Historicamente, diversos autores concentravam a definição de gestão por competências em torno de alguns aspectos, como formação, resultados e interação. Bitencourt (2004), apresenta um quadroresumo das principais correntes de pensamento sobre a gestão por competências: 


\begin{tabular}{|l|l|}
\hline \multicolumn{1}{|c|}{ ASPECTOS ABORDADOS } & \multicolumn{1}{c|}{ PRINCIPAIS AUTORES } \\
\hline Formação & $\begin{array}{l}\text { Boyatizis (1982), Parry (1996), Boog (1995), Becker (2001), Spencer e Spencer } \\
(1993), \text { Magalhães et al. (1997), Hipólito (2000), Dutra et al. (1998), Sandberg } \\
(1996)\end{array}$ \\
\hline Capacitação (aptidão) & Moscovici (1994), Magalhães et al. (1997), Dutra et al. (1998), Zarifian (2001) \\
\hline Ação (em oposição a potencial) & $\begin{array}{l}\text { Sparrow e Bognanno (1994), Durand (1998), Cravino (1997), Ruas (1999), } \\
\text { Moscovici (1994), Boterf (1997), Perrenoud (1998), Fleury e Fleury (2000), } \\
\text { Davis (2000), Zarifian (2001) }\end{array}$ \\
\hline $\begin{array}{l}\text { Articulação de recursos } \\
\text { (mobilização) }\end{array}$ & Boterf (1997) \\
\hline Resultados & $\begin{array}{l}\text { Boyatizis (1982), Sparrow e Bognanno (1994), Parry (1996), Hase et al. (1998), } \\
\text { Becker et al. (2001), Spencer e Spencer (1993), Cravino (2000), Ruas (1999), } \\
\text { Fleury e Fleury (2000), Hipólito (2000), Dutra et al. (1998), Davis (2000), } \\
\text { Zarifian (2001) }\end{array}$ \\
\hline $\begin{array}{l}\text { Perspectiva } \\
\text { (questionamento constante) }\end{array}$ & Hipólito (2000) \\
\hline Autodesenvolvimento & Bruce (1996) \\
\hline Interação & Sandberg (1996) \\
\hline
\end{tabular}

Quadro 1 - Aspectos abordados pelas diferentes abordagens sobre gestão de competências Fonte: Bitencourt (2004, p.59).

A forma como o mercado de trabalho foi se modificando com questões do ambiente geral, a intensificação da competitividade e a necessidade de flexibilidade, fez com que as organizações buscassem um modelo mais adequado para lidar com essas questões. Nesse contexto, há três principais mudanças no mercado que justificam a necessidade de adoção dos modelos de competências para a administração de empresas. O primeiro é o sentido de situação, que se refere ao que acontece de modo não planejado, influenciando as rotinas normais da organização, modificando o processo de melhorias dos processos e lançando desafios a realização do trabalho; essa mudança afirma a importância das competências em todos os momentos, ao invés de se manifestar apenas no início das tarefas, devido a essa imprevisibilidade, o colaborador precisa estar sempre preparado para lidar com as situações adversas, propor soluções e resolver o que lhe compete.

A segunda mudança é a comunicação, que vai além da comunicação interpessoal e do entendimento do outro, englobando também a compreensão de si mesmo e a coerência com a estratégia, o objetivo e as mensagens da organização. A última é o sentido de serviço, que se caracteriza pelo atendimento ao cliente, seja ele interno ou externo da empresa, precisando ser centralizado para que esteja presente em todas as ações tomadas; o autor também destaca o papel da comunicação para lidar com essa terceira mudança, já que é por meio de uma boa estrutura de comunicação que será possível prestar um bom serviço (DUTRA, C., 2017).

Com o surgimento de formas mais recentes de administrar, percebeu-se que o colaborador não é necessariamente competente, mas ele está competente diante de determinada situação. A partir de uma análise das competências durante a rotina de trabalho é constatado que o mesmo conjunto de conhecimentos, habilidades e atitudes diferem do resultado entregue pelo mesmo funcionário, o que consequentemente aponta para uma variação do desempenho dele. Essa afirmação reforça a necessidade de um modelo de gestão integrado dos atributos, do desempenho e da capacidade do colaborador para que a organização esteja consciente dos fatores que causam essa variação e de quais ações podem ser tomadas para lidar com eles, desenvolvendo profissionais que sejam capazes de lidar com as diversas situação do dia a dia.

A gestão por competências objetiva investir e impulsionar o desenvolvimento dos funcionários em suas competências, qualificando-os em outras e melhorando as que já existem. Baseia-se na mobilização das competências de cada colaborador, organizando-as coletivamente para atingir os objetivos organizacionais. É considerada mais eficiente do que os modelos tradicionais quando o trabalhador tem consciência dos benefícios que um bom perfil de competências pode contribuir para a organização e para a sua vida profissional (TRIDAPALLI, 2017). 


\section{Gestão por Competências e Desenvolvimento Profissional}

Antes de 1990, a ideias sobre o desenvolvimento do indivíduo no ambiente de trabalho estavam concentradas em ações de capacitação e aperfeiçoamento. Então, houve uma modificação nessa linha de pensamento para a ideia de melhoria contínua da qualificação profissional, aproximando-se da noção de desenvolvimento profissional (DP). O DP passou a assumir um significado mais amplo dentro das organizações, referindo a um conjunto de ações relacionadas a aprendizagem para auxiliar a empresa e os funcionários a alcançarem os seus objetivos. Assim, o DP pode ser entendido com o resultado das ações de aprendizagem que permitem aos indivíduos ampliar suas competências para a atuação no trabalho (MONTEIRO; MOURÃO, 2017).

A competência surgiu como um dos principais meios que possibilitam o desenvolvimento profissional (APERIA, 2017), o que implica dizer que a organização que gere as pessoas considerando suas competências dispõe de mais possibilidades de desenvolvê-las, aproveitando melhor seus conhecimentos, habilidades e atitudes e recebendo resultados que agregam mais valor. Isso se justifica pelo fato de que esse modelo vai além da qualificação, levando em conta a questão comportamental, as particularidades dos indivíduos e o desenvolvimento de profissionais que deixam de estar limitados aos seus cargos e passam a ser multitarefas.

Com o avanço da gestão por competências, o trabalho deixa de ser visto da forma tradicional, ou seja, deixa de ser um conjunto de tarefas e responsabilidades relativas ao cargo, passando a ser "o prolongamento direto da competência que a pessoa mobiliza diante de uma posição profissional cada vez mais recíproca e complexa" (DUTRA, C., 2017, p. 73). Diante disso, as funções exercidas pelo trabalhador deixam de ser especializadas em um único conjunto de tarefas, e passam a se caracterizar pela flexibilidade e variedade, que estão sob a dever do funcionário, e em outros contextos, passam também a englobar novas responsabilidades resultantes de novos conhecimentos e tecnologias disponíveis no mercado.

Por sua vez, os profissionais envolvidos com a gestão por competências deixam de entender o aperfeiçoamento do colaborador de forma estática, em que acredita-se que os treinamentos e capacitações pontuais são suficientes, e passam a considerar a formação profissional como um processo contínuo de aquisição de conhecimentos, habilidades e atitudes, ou seja, de competências que precisam ser administradas para proporcionar o crescimento do colaborador (PIMENTEL, 2017). A gestão baseada em competências influencia no desenvolvimento profissional do colaborador, pois com seu crescimento no trabalho, o indivíduo tende a assumir novas responsabilidades, atribuições mais complexas e a agregar mais valor à organização (CERIBELI et al., 2019). Sendo assim, torna-se capaz de realizar entregas com mais qualidade, e desta forma, a gestão das competências acaba favorecendo tanto a empresa, com melhores resultados, quanto a pessoa, como um profissional mais preparado para lidar com as exigências do mercado e de seu trabalho.

Portanto, pode-se entender a gestão por competências como um modelo que permite aos gestores reconhecer as competências necessárias para que se realize o trabalho, e as que os funcionários possuem, para que seja possível traçar um plano de desenvolvimento individual, a fim de desenvolvêlo profissionalmente e maximizar a sua contribuição para a empresa. Para os fins desse artigo, adotase a ideia de que uma organização que gerencia seus funcionários através de competências possui mais possibilidades de desenvolvê-los profissionalmente do que aquelas que adotam a gestão tradicional baseada em atribuições rígidas e voltadas a atender apenas aos requisitos dos cargos, pois como afirma Pimentel (2017), para que se contribua para o desenvolvimento profissional, a formação do funcionário deve ser um processo contínuo de aquisição e administração de competências pela organização, culminando no seu crescimento, principalmente no ambiente industrial, que está frequentemente passando por mudanças, devido a novas tecnologias e exigências do mercado. 


\section{Gestão por Competências na Indústria 4.0}

A indústria 4.0 pode ser definida como a "crescente digitalização de toda a cadeia de valor e da interligação resultante de pessoas, objetos e sistemas através da troca de dados em tempo real" (GRZYBOWSKA; LUPICKA, 2017, p. 250, tradução nossa). Essa definição apresenta elementos essenciais ao sucesso das indústrias que passam a modernizar seus processos com base nesse preceito. Os objetos ou recursos e os sistemas são fatores estratégicos para as empresas, que precisam lidar com eles de forma integrada com a estrutura da organização e os objetivos que se deseja alcançar. Já as pessoas, elas devem estar alinhadas com essa evolução, por meio de um modelo de gestão que abranja suas características particulares e permita o seu desenvolvimento para que possam ser capazes de lidar com as novas perspectivas que surgirem.

Para Yanai et al. (2017), o termo indústria 4.0 surge para representar a quarta revolução industrial, sucedendo as três anteriores. A primeira introduziu a mecanização da produção através das máquinas a vapor. A segunda se caracterizou pela produção em massa, divisão do trabalho e pelo uso da energia elétrica, passando a integrar as indústrias existentes com base nos modelos de produção tayloristafordista. A terceira englobou a eletrônica, a automação dos processos de produção e a implantação da tecnologia da informação. Por fim, a quarta e atual revolução industrial é impulsionada pelas tecnologias da chamada indústria 4.0 que vieram para deixar os processos mais inteligentes e acaba por valorizar mais o conhecimento da pessoa ou invés da sua técnica. Essa característica da quarta revolução industrial exige mais do que trabalhadores que apenas executem suas tarefas, mas que também entendam, saibam fazer e que queiram fazer, ou seja, indivíduos que possuem as capacidades e competências adequadas a esse novo formato.

As mudanças provocadas pela indústria 4.0 influenciam não apenas os processos de produção, mas também todas as áreas da organização (ENKE, 2018). Entre os elementos que compõem essas áreas, as pessoas são as que mais precisam estar adequadas a esse novo modelo. Nesse contexto, a gestão por competências permite que sejam trabalhadas as mudanças nos atributos de cada indivíduo, já que os perfis de competência para essa nova indústria estão deixando de ser apenas técnicos, e incluindo mais as competências humanas.

Para o trabalho humano na indústria 4.0, as competências devem ter um caráter técnico, metodológico, social e pessoal, ou seja, de saber fazer, ligadas a métodos, de relacionamento e particular ao indivíduo. Como discutido no parágrafo anterior, o perfil de competências se torna mais complexo visto que, para a indústria 4.0, possui relação aos aspectos de informação, dados, novas tecnologias e procedimento e gestão (SILVA; KOVALESKI; PAGANI, 2019).

Dessa forma, os funcionários envolvidos precisam estar constantemente se aprimorando, a fim de se manterem direcionados e focados nas modificações que ocorrem em sua organização. Devido à valorização do conhecimento no lugar da técnica, a regulação das capacidades dos funcionários por meio de uma gestão estruturada das competências possibilita, como argumentam Derrosso e Boewerk (2017), a evolução em conjunto com as outras áreas da empresa, ao invés de manter o foco apenas na eficiência da produção.

Assim, a adoção da gestão de pessoas por competências na indústria 4.0 se justifica pela necessidade de um modelo que facilite alinhar as competências técnicas necessárias para lidar com a operação das novas tecnologias e as competências humanas, que possibilite criar redes integradas de relacionamento e comunicação com as outras áreas da empresa e que facilite o entender melhor das informações e do funcionamento dessas tecnologias. Por meio desse modelo de gestão, a organização pode trabalhar melhor o desenvolvimento e alocação dessas competências junto as mudanças na produção.

Com a quarta revolução industrial, os negócios dinâmicos e os processos inteligentes requerem pessoas que possam responder de forma flexível e com rapidez as mudanças mais frequentes, demandando o investimento no desenvolvimento profissional dos funcionários, a fim de torná-los capazes de solucionar problemas e contribuir com sua experiência, habilidades e comportamento para a evolução dos processos (GRZYBOWSKA; LUPICKA, 2017). 


\section{Procedimentos metodológicos}

Quanto à natureza, a presente pesquisa é classificada como aplicada, visto que procura gerar conhecimentos úteis para aplicação prática e voltados a solução de questões específicas (PRODANOV; FREITAS, 2013). Por meio da análise da gestão por competências, buscou-se contribuir para o desenvolvimento profissional dos colaborados de empresas que estão implantando o formato da indústria 4.0.

Quanto aos objetivos, esse estudo pode ser classificado como exploratório por buscar novas ideias e maior familiaridade com o tema, proporcionando mais informações sobre o que será estudado e com isso, facilitando a delimitação do tema. Os estudos exploratórios são bastante utilizados para explorar alternativas e fazer o diagnóstico de situações específicas (OLIVEIRA, 2011). Três principais características são descritas por Prodanov e Freitas (2013), a saber: geralmente envolve levantamento bibliográfico; entrevistas com indivíduos que possuem experiência com o problema de pesquisa; e a análise de exemplos úteis ao entendimento do assunto. Especificamente, buscou-se examinar conceitos que possam estabelecer uma maior familiaridade da gestão por competências com empresas adotantes da indústria 4.0 e, com base nessa relação, explorar formas de contribuir com o desenvolvimento da organização e dos colaboradores.

A abordagem foi qualitativa, ou seja, o ambiente natural é a principal fonte de coleta de dados, onde o importante é a interpretação do pesquisador sobre o fenômeno em estudo (PEREIRA et al., 2018). Desse modo, através do estudo qualitativo procurou-se entender melhor a realidade da empresa em termos de gestão de pessoas e o quanto a indústria 4.0 influencia no conjunto de competências necessárias a esse novo formato.

Outras características da abordagem qualitativa, segundo Ludke e Andre (2013), são: a coleta ocorre no ambiente natural e o pesquisador é o instrumento principal; a preocupação do processo é mais importante do que a do produto; e as opiniões e interpretações que as pessoas dão as coisas são o foco de atenção. No presente estudo, o método qualitativo proporcionou ao pesquisador estar mais próximo das pessoas que fazem parte da pesquisa, além considerar os significados particulares que elas darão as situações existentes, possibilitando a captura das suas percepções e atribuições do ambiente.

Como método de coleta de dados, foi escolhido a entrevista semi-estruturada por permitir certo grau de liberdade durante a entrevista e por ser útil na coleta de dados qualitativos. De acordo com Oliveira (2011), a entrevista semi-estruturada apresenta um roteiro que estrutura as perguntas que serão feitas a cada entrevistado, sendo suas principais vantagens: o roteiro é composto de perguntas suportadas em teorias que interessam a pesquisa; o entrevistador é livre para escolher como perguntar; e a ordem das perguntas podem variar a fim de se adequar as características de cada entrevistado.

As entrevistas foram feitas com seis colaboradores do setor administrativo da empresa, que devido ao pedido de anonimato dela será nomeada neste artigo de PS. Esses colaboradores foram escolhidos por lidarem com as principais situações referentes a gestão da empresa. Para manter o anonimato, os seis entrevistados serão representados por E1, E2, E3, E4, E5 e E6.

A PS é uma empresa do setor industrial alagoano que trabalha com a fabricação e o comércio dos seus produtos. Possui uma orientação voltada principalmente para a qualidade, o que a leva a estar sempre focada nos resultados, inspeções dos produtos e com o suporte técnico para os seus clientes. Além do foco em qualidade, a intensificação da competitividade e os avanços tecnológicos fizeram com que ela se preocupasse em modernizar a sua produção, iniciando o processo de adesão ao formato da indústria 4.0, o que a torna a organização adequada para os fins desse artigo.

No quadro 2 pode-se visualizar as categorias analíticas definidas a priori. Para a análise dos dados adotou-se a análise de conteúdo, que pode ser definida como um conjunto de instrumentos metodológicos aplicados a análise de fontes de conteúdo diversas, verbais ou não verbais (SILVA; FOSSÁ, 2015). 


\begin{tabular}{|c|c|c|}
\hline Categorias de análise & Definição conceitual & Definição operacional \\
\hline $\begin{array}{l}\text { Modelo de gestão por } \\
\text { competências }\end{array}$ & $\begin{array}{l}\text { Desenvolvimento dos funcionários } \\
\text { em suas competências, qualificando- } \\
\text { os em outras e melhorando as que já } \\
\text { existem. }\end{array}$ & $\begin{array}{l}\text { Mapa de competências organizacionais, lista das } \\
\text { competências individuais, software de gestão de } \\
\text { pessoas, programas de desenvolvimentos de } \\
\text { competências, indicadores de necessidade de } \\
\text { conhecimento e desenvolvimento de } \\
\text { competências e organização das funções por } \\
\text { competências. }\end{array}$ \\
\hline $\begin{array}{l}\text { Desenvolvimento } \\
\text { profissional }\end{array}$ & $\begin{array}{l}\text { Conjunto de ações relacionadas a } \\
\text { aprendizagem para auxiliar a empresa } \\
\text { e os funcionários a alcançarem os seus } \\
\text { objetivos. }\end{array}$ & $\begin{array}{l}\text { Presença de ações e planos de desenvolvimento } \\
\text { individual (PDI), programas de capacitação e } \\
\text { treinamentos e incentivos a formação } \\
\text { profissional. }\end{array}$ \\
\hline $\begin{array}{l}\text { Gestão } \\
\text { competências } \\
\text { indústria } 4.0\end{array}$ & $\begin{array}{l}\text { Alinhamento das competências } \\
\text { técnicas necessárias para lidar com a } \\
\text { operação das novas tecnologias e as } \\
\text { competências humanas, que } \\
\text { possibilite criar redes integradas de } \\
\text { relacionamento e comunicação com } \\
\text { as outras áreas da empresa. }\end{array}$ & $\begin{array}{l}\text { Ferramentas de gestão e desenvolvimento de } \\
\text { competências da indústria 4.0, incentivo a } \\
\text { criatividade, registro de conhecimentos técnicos, } \\
\text { programas de capacitação das novas tecnologias } \\
\text { e software (ERP) de gestão integrada das áreas } \\
\text { organizacionais. }\end{array}$ \\
\hline
\end{tabular}

Quadro 2 - Categorias de análise

Fonte: Elaborado pelos autores com base no referencial teórico.

\section{Apresentação e análise dos resultados}

Com base nas respostas obtidas no processo de coleta de dados, foi feito o levantamento das competências individuais que os entrevistados acreditam que possuem e quais eles consideram importantes para uma empresa que está em transição para o formato de indústria 4.0. As respostas obtidas foram organizadas no quadro 3 :

\begin{tabular}{|c|c|c|}
\hline Cargo & Competências que possui & $\begin{array}{l}\text { Competências que acredita ser } \\
\text { necessárias para a indústria } 4.0\end{array}$ \\
\hline $\begin{array}{l}\text { Gerente Financeiro/ } \\
\text { Administrativo }\end{array}$ & $\begin{array}{l}\text { Liderança, planejamento financeiro e de vendas, } \\
\text { conhecimentos de importação e câmbio, } \\
\text { conhecimentos mercadológicos, análise de crédito, } \\
\text { técnicas de fabricação e de vendas e negociação } \\
\text { bancária. }\end{array}$ & $\begin{array}{l}\text { Aptidão tecnológica, conhecimento } \\
\text { de produção tecnológica e visão } \\
\text { sistêmica. }\end{array}$ \\
\hline $\begin{array}{l}\text { Analista } \\
\text { Qualidade }\end{array}$ & $\begin{array}{l}\text { Negociação, proatividade, conhecimento técnico e } \\
\text { gestão. }\end{array}$ & Planejamento e gestão de mudanças. \\
\hline $\begin{array}{l}\text { Supervisora } \\
\text { Financeira }\end{array}$ & Gestão financeira, comunicação e proatividade. & $\begin{array}{l}\text { Organização, iniciativa e propensão a } \\
\text { desafios. }\end{array}$ \\
\hline $\begin{array}{l}\text { Assistente } \\
\text { Financeira }\end{array}$ & $\begin{array}{l}\text { Organização, responsabilidade, pontualidade, } \\
\text { Assiduidade e criatividade. }\end{array}$ & $\begin{array}{l}\text { Organização, planejamento } \mathrm{e} \\
\text { criatividade. }\end{array}$ \\
\hline $\begin{array}{l}\text { Programador de } \\
\text { Produção }\end{array}$ & $\begin{array}{l}\text { conhecimento técnico e de produto, aptidão } \\
\text { tecnológica, relacionamento interpessoal, iniciativa. }\end{array}$ & $\begin{array}{l}\text { Conhecimentos tecnológicos } \\
\text { autoaperfeiçoamento. }\end{array}$ \\
\hline $\begin{array}{l}\text { Assistente } \\
\text { Administrativo }\end{array}$ & Habilidades manuais, conhecimento técnico. & $\begin{array}{l}\text { Visão sistêmica, conhecimentos } \\
\text { mercadológicos, } \\
\begin{array}{l}\text { planejamento, } \\
\text { clendimento ao } \\
\text { responsabilidade. }\end{array}\end{array}$ \\
\hline
\end{tabular}

Quadro 3 - Levantamento de competências e necessidades

Fonte: Elaborado pelos autores.

Diante do obtido, percebe-se que existe uma disparidade das competências que os funcionários possuem com as que eles acreditam ser importantes para esse momento de mudança da empresa. Quando perguntado o porquê dessas diferenças, foi constatado que as justificativas se agrupavam em: 
no modelo atual de gestão baseada em cargos e na carência de treinamentos e capacitações direcionados ao desenvolvimento dessas competências consideradas necessárias aos colaboradores. Os entrevistados acreditam que a forma atual em que está sendo feita a gestão de pessoas na empresa não consegue diminuir essa lacuna entre as competências existentes e as que eles consideram essenciais na uma empresa que está se encaixando nos moldes da indústria 4.0, sendo necessário tomar medidas que possibilitem diminuir essa disparidade.

Como apontado por Silva, Kovaleski e Pagani (2019), a quarta revolução industrial traz consigo a necessidade de competências de caráter mais intelectual e da valorização do conhecimento, da parte tecnológica e analítica e do comportamento do colaborador, isso se constata em algumas das respostas dadas pelos entrevistados, que indicam competências nesse sentido, como por exemplo iniciativa, visão sistêmica, planejamento, conhecimentos e aptidão tecnológica, gestão de mudança, propensão a desafios, criatividade, organização e responsabilidade.

Baseado nas competências bases para pessoas na indústria 4.0 definidas por Silva, Kovaleski e Pagani (2019, p. 122), foi solicitado que os entrevistados ordenassem essas competências, em ordem crescente de importância no contexto atual da empresa. De acordo com esses autores, essas competências são necessárias para o trabalho, visto que fazem a integração das pessoas com os recursos físicos e digitais, além de torná-las mais preparadas para atuar nos diferentes níveis organizacionais. Através das notas atribuídas as competências foram organizadas em um ranking, exibido na figura 1:

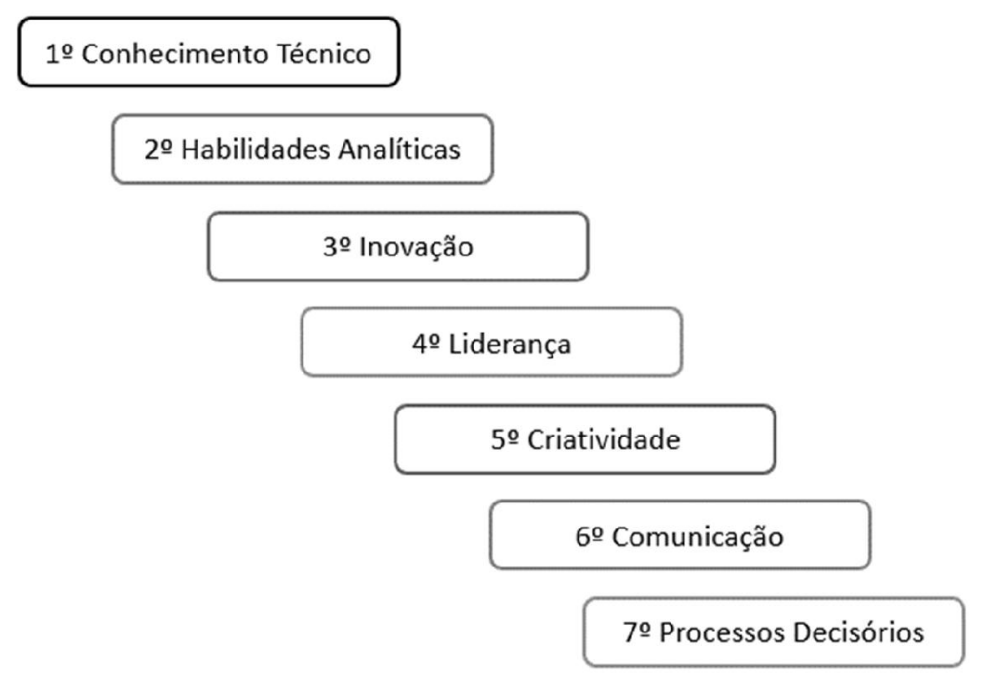

Figura 1 - Ranking das competências bases para pessoas na indústria 4.0

Fonte: Elaborado pelos autores com base na pesquisa de campo e nas competências levantadas por Silva, Kovaleski e Pagani (2019).

Das competências listadas por Silva, Kovaleski e Pagani (2019), todos os entrevistados acreditam ter criatividade e serem capazes de articular formas diferentes de interagir e propor soluções. Os respondentes afirmam possuir conhecimento técnico e acreditam que essa competência é essencial frente as mudanças que estão acontecendo na empresa e para o uso de novas tecnologias.

A competência habilidades analíticas é percebida como muito importante para as pessoas de uma indústria no formato 4.0, devido a necessidade de compreender o cenário tecnológico e as formas de melhorar os processos. A maioria dos entrevistados afirmou que a possui, enquanto os outros responderam que precisam melhorá-la. A inovação, embora tenha sido ordenada pelos respondentes como a terceira mais importante, apenas um deles afirmou a possuir, o E5 declarou: "com a inovação você vai moldar, você vai implantar novas máquinas, novos funcionários, novos tipos de trabalho, buscando criar novas coisas, que são muito importantes para sempre melhorar o que já existe.”

De acordo com eles, o que falta na organização é o incentivo e capacitações para desenvolver essa 
competência, E6 relatou que "ainda falta investimentos para chegar no nível esperado de inovação, nas pessoas e na estrutura', pois muito se fala em inovação, mas pouco se faz quanto ao real uso dela no dia a dia da empresa".

Comunicação e liderança, embora tenham sido classificadas pelos respondentes, respectivamente, como a sexta e a quarta competências mais importantes, foram tidas por eles como competências que necessariamente se relacionam, de forma que uma não funciona bem sem a outra. Corroborando, o E5 disse: "para que você seja um bom líder, você precisa saber se comunicar. Passar as informações para os seus funcionários facilita o comando e ajuda a fazer melhor o trabalho".

Com exceção do E6 os outros entrevistados não se sentem aptos para a competência processos decisórios. Eles acreditam que precisam de maior autonomia para desenvolvê-la, pois a fase inicial de qualquer mudança que venha a acontecer na organização é uma oportunidade de desenvolvimento de novas competências e aperfeiçoamento das existentes, porém, de acordo com o relato da E1, o que geralmente acontece é a concentração do processo decisório na alta direção, devido ao receio de delegar certo nível de responsabilidade as pessoas que não estão totalmente sob o controle da diretoria. As competências listadas acima foram percebidas como capazes de integrar as novas tecnologias com a parte humana dentro da organização, como Grzybowska e Lupicka (2017) afirmam ao falarem que a dinamicidade dos negócios e os processos inteligentes exigem competências que possibilitem criar redes integradas de relacionamento entre as pessoas e os outros recursos organizacionais, como os tecnológicos. Foi apontada a necessidade em mobilizar esforços para o desenvolvimento de competências da indústria 4.0, devido ao pouco incentivo a criatividade, de programas de capacitação de novas tecnologias e do registro de conhecimentos técnicos.

Embora existam pontos indicados pelos entrevistados como de melhorias, foi verificado nesses colaboradores que eles reconhecem a importâncias dessas competências, como apontado pelo E6: "trabalhar com competências pode colocar as pessoas no caminho do aperfeiçoamento".

Para fundamentar a relevância da gestão por competências, foi perguntado qual a percepção dos entrevistados sobre a importância desse modelo na empresa que eles trabalham. Todos os respondentes afirmaram a necessidade dessa forma de gerir pessoas, conversando com o que dizem Scarpelli e Lima (2018), de que essa forma de gerir pessoas é importante por considerar os conhecimentos, as habilidades e as atitudes das pessoas e, por meio dela, a empresa conseguirá fazer o uso adequado das competências individuais já existentes para a realização do trabalho. Em complemento, a E3 afirmou que esse modelo traz uma abordagem completa e que a gestão por competências contribui para "desenvolver o pessoal no setor que lhe compete", e a E2 coloca: "tem que ter, para colocar as pessoas certas no lugar certo".

Outro ponto a se destacar é a importância de ter profissionais multifuncionais na empresa, capazes de desempenhar diferentes atividades. O E6 confirmou a necessidade de um modelo que administre os recursos humanos desenvolvendo a multifuncionalidade, visto que a empresa já demando isso dos seus funcionários, em que "a analista de qualidade cuida das compras, o programador de produção é responsável pela logística e o administrador financeiro administra as vendas" (E6). Nessa perspectiva, o trabalho de Ceribeli e Almeida (2015) propõe que o modelo de gestão por competência é capaz de alinhar as práticas de gestão de pessoas à multifuncionalidade, permitindo aproveitar e desenvolver os colaboradores em diversas funções que vão além dos limites estipulados pelos cargos.

Atualmente, a organização estudada não utiliza a gestão por competências como a literatura apresenta, ou seja, com o desenvolvimento dos funcionários em suas competências e com o foco na entrega de valor (DUTRA, J., 2017). Verificou-se a ausência de indicadores de gestão de pessoas de softwares próprios para a gestão e ao desenvolvimento de competências. O E6 respondeu que a empresa ainda precisa crescer nesse sentido, pois a gestão baseada em cargos não está sendo suficiente para esse momento de transição. Nessa mesma direção o E4 afirmou que: "o modelo de competências seria necessário para o avanço para o 4.0, porque na minha opinião a gestão de cargos, para a gente hoje, ela está com falhas. Nem todo mundo que está exercendo um certo cargo tem a competência e a experiência para assumir."

Embora não possua um documento com as competências individuais de cada funcionário, a empresa 
possui uma matriz de competências, onde cada colaborador é acompanhado por meio de competências padronizadas para todos. De acordo com o relato da E3, é por meio dessa matriz que a organização decide quais cursos, capacitações e treinamentos terá que realizar durante o ano, "com competências que são avaliadas e que os diretores precisam fazer algo para melhorar as que precisam" (E3). Essa matriz é um documento importante porque indica o interesse em trabalhar com um modelo de gestão de pessoas que vá além dos cargos, porém cabe destacar que é válido a organização das competências individuais para que possam ser organizadas coletivamente a fim se atender as expectavas de competências organizacionais (DUTRA, C., 2017).

Como forma de aproveitar as competências individuais no trabalho, a E3 sugere: "ter conhecimento do que possui para poder direcionar melhor o trabalhador". Desse modo, pode-se incentivar a disseminação de conhecimento por meio capacitações e treinamentos, a fim de informar os funcionários sobre o potencial de cada um. As pessoas devem agir como agentes de transformação, entregando valor para empresa, não bastando realizar apenas o trabalho especificado, mas também superando desafios e agindo ativamente para melhorar os processos existentes (DUTRA, J., 2017). Nesse sentido, foi enfatizado também a necessidade de a organização proporcionar os recursos para o desenvolvimento profissional de cada colaborador e para superar desafios, como também maior autonomia para a tomada de decisões para a melhora do ambiente de trabalho, como a E1 sugere: "com um ambiente sem interrupções, próprio para se concentrar, com acesso ao que se precisa e liberdade para decisões".

Devido ao momento de transição para o formato de indústria 4.0, foi questionado como as competências de cada entrevistado podem auxiliar a empresa no dia a dia. A E1 respondeu que suas competências podem ser o primeiro passo para a "inovação em seus setores, das regras e da gestão"; a E2 disse: facilitando processos e procurando soluções"; enquanto E5 relatou: "com novas metodologias, novos métodos de trabalho e de projetos". As sugestões apresentadas conversam com o que dizem Scarpelli e Lima (2018), no sentido de que cada indivíduo é capaz de usar suas competências para mobilizar e transformar seus conhecimentos e experiências em ações, dessa forma, os funcionários acreditam que essas ações são um potencial de inovação útil nesse momento de mudanças.

Sobre a forma com que a organização desenvolve as competências individuais dos seus colaboradores, o discurso predominante é de que não há esforços nesse sentido. As capacitações e treinamentos existentes são específicos para as necessidades mais imediatas, como o manuseio de uma nova máquina, o aperfeiçoamento de um processo existente e/ou o treinamento operacional para funcionários novos e para aqueles que mudam de cargo ou função. Uma forma apontada do que a empresa acredita ser eficiente para o desenvolvimento de competências é o incentivo a formação superior através de financiamento. Contudo, cabe ressaltar que a competência é a interseção de conhecimento, habilidade e atitude (DERROSSO; BOEWERK, 2017). Dessa forma, o investimento somente no conhecimento não é suficiente, pois cabe ainda o desenvolvimento da habilidade e o comportamento ativo do indivíduo em querer desenvolver a competência, ou seja, a atitude.

Foi destacado também pelos entrevistados o papel do colaborador como agente do seu próprio desenvolvimento profissional, pois como foi dito pelo E6: "o aperfeiçoamento e o crescimento depende mais das pessoas", visto que como a competência individual é mais singular e particular de cada indivíduo, ela está intimamente ligada ao desenvolvimento profissional individual. De forma conjunta, os entrevistados acreditam que o adequado é o funcionário apresentar interesse em desenvolver suas competências e a organização investir em formas de desenvolvê-lo profissionalmente, alinhando-se a Ceribeli et al. (2019) que apresentam a gestão baseada em competências como uma alternativa capaz de prepará-lo para atribuições mais complexas e a agregar valor à organização.

Foi questionado de que maneira a gestão por competências pode contribuir para o desenvolvimento profissional de cada entrevistado, cujas respostas foram consolidadas na figura 2 : 


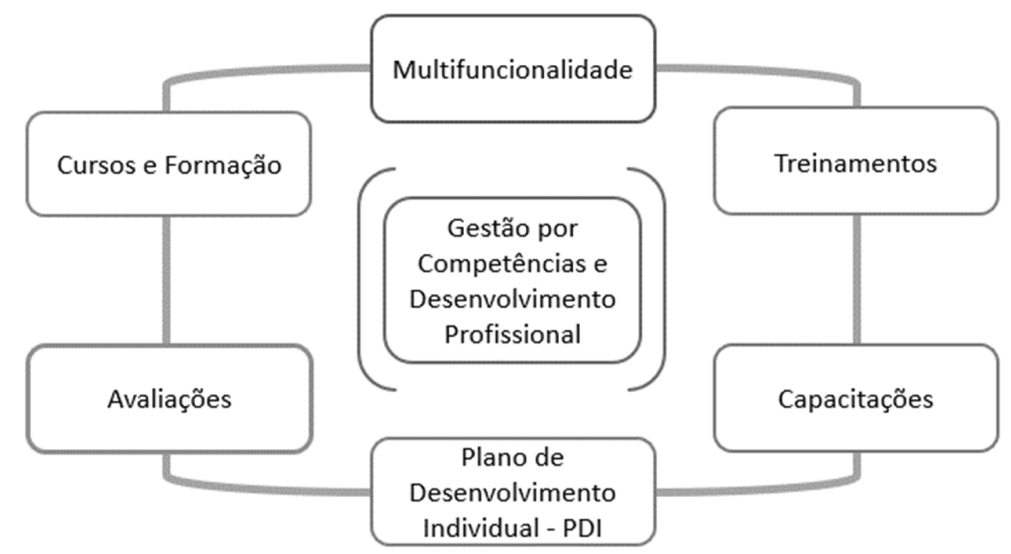

Figura 2 - Elementos de contribuição da gestão por competências para o desenvolvimento profissional com base na pesquisa de campo

Fonte: Elaborado pelos autores.

Algumas das respostas dadas sinalizam dimensões de modelos de gestão de pessoas tradicionais tais como, treinamentos, capacitações, cursos e formação e avaliações. A E2 apontou: "treinamentos, capacitações e cursos para a formação de um bom profissional"; em confirmação, o E5 apontou: "treinamento e capacitação". Acredita-se que mesmo com as mudanças das necessidades dos colaboradores, essas formas típicas ainda são consideradas "eficientes para desenvolver qualquer funcionário" (E5), para o desenvolvimento profissional e, como dito pelo E6 "seria um grande ganho se houver avaliação para ter conhecimento do que melhorar", a avaliação do funcionário funcionaria como um instrumento que mede as necessidades de desenvolvimento. Desta forma, esses elementos sugeridos junto a gestão por competências, podem direcionar esforços e investimentos para a aquisição de novos conhecimentos, habilidades e atitudes em um processo contínuo de crescimento do colaborador (PIMENTEL, 2017).

Destacam-se ainda a multifuncionalidade e o plano de desenvolvimento individual (PDI). A primeira resposta, dita pelo E6 como "uma contribuição para superar as exigências do dia a dia", complementa o que foi exposto por Carbone et al. (2009), de que trabalhadores multifuncionais são necessários nas organizações, pois contribuem para a melhoria da produção e que esta deve ter um modelo de gestão de pessoas capaz de lidar com as particularidades dos indivíduos, por outro lado, o funcionário também sai ganhando, visto que será capaz de executar múltiplas tarefas, tornando-se polivalente.

Por fim, a segunda resposta e último elemento respondido é conceituada pela E4 como "uma meio de atender a pessoa e atribuir maior crescimento"; e apontada pela E1 como uma "atenção individual", traz o PDI como uma alternativa para que os colaboradores possam se desenvolver na sua carreira, como também as competências necessárias para assumir determinadas responsabilidades dentro da organização. É um instrumento interessante pois como afirma Pimentel (2017), ao ser aplicado nos moldes da gestão por competências, possibilita o acompanhamento do profissional em um processo contínuo de administração de competências pela organização, resultando no seu crescimento, o que é extremamente importante no ambiente industrial, que está sempre sujeito a mudanças tecnológicas, novas formas de produção e demanda por trabalhadores capazes lidar com esses fatores.

\section{Considerações finais}

Esse artigo se propôs a responder à pergunta de pesquisa: como a gestão por competências pode contribuir para o desenvolvimento profissional dos funcionários de uma empresa do setor industrial? Assim, como o objetivo geral: identificar a contribuição do modelo de gestão por competências para o desenvolvimento profissional dos funcionários de uma empresa que está na fase inicial de implantação dos conceitos da indústria 4.0. 
A metodologia adotada foi de pesquisa aplicada, exploratória e qualitativa, pois acredita-se que esse direcionamento é adequado para responder à pergunta de pesquisa e atingir o objetivo geral. $\mathrm{O}$ instrumento de pesquisa adotado foi a entrevista semi-estruturada, devido a maior liberdade para a coleta de dados e a análise foi feita focada nas categorias definidas com base no método análise de conteúdo (BARDIN, 2011).

Os objetivos específicos desse artigo são: verificar como a empresa utiliza as competências na gestão de pessoas, fazer um levantamento das competências dos funcionários do setor administrativo e sugerir formas de contribuir para o desenvolvimento dos funcionários baseadas na gestão por competências. Eles foram considerados e discutidos na análise dos resultados vinculados as categorias definidas na metodologia.

De acordo com as respostas obtidas nas entrevistas, a gestão por competências pode contribuir para o desenvolvimento profissional por incentivar capacitações, treinamentos, cursos e formação, avaliações, por desenvolver profissionais multifuncionais e por propor o PDI para cada funcionário. Além desses elementos, foi apontado a autonomia confiada aos colaboradores em suas áreas de competência e por gerir cada indivíduo considerando suas particularidades.

As limitações identificadas foram a incapacidade de entrevistar todos os colaboradores do setor administrativo, de obter respostas mais detalhadas e a impossibilidade de realizar uma análise documental em busca de instrumentos e ferramentas voltados a gestão por competências existentes na organização, devido a empresa estar passando por um momento de estruturação de uma área de recursos humanos. Sugere-se mais estudos que relacionem a gestão por competências, o desenvolvimento profissional e a indústria 4.0, a fim de contribuir com estudos para organizações que queiram desenvolver seus colaboradores, como também para a expandir a literatura.

Esse artigo conseguiu fazer um levantamento das competências individuais do entrevistados, classificadas de acordo com o cargo dos respondentes, e das competências tidas com importantes para uma empresa que está em transição para o formato 4.0; contribuiu para o trabalho de Silva, Kovaleski e Pagani (2019) ao apresentar um ranking das competências levantadas por esses autores, apresentou a percepção dos entrevistados sobre a gestão por competências e expos os elementos de contribuição da gestão por competências para o desenvolvimento profissional.

Por meio deste artigo, foi possível atingir todos os objetivos propostos e contribuir para que as organizações que estejam passando por situações de mudança semelhantes, possam ter um apoio empírico para adotar práticas de gestão de pessoas por competências e para que outros autores possam ter um apoio teórico em seus trabalhos.

\section{Referências}

AIRES, Regina Wundrack do Amaral; KEMPNER-MOREIRA, Fernanda; FREIRE, Patricia de Sá. Indústria 4.0: desafios e tendências para a gestão do conhecimento. In: SEMINÁRIO UNIVERSIDADES CORPORATIVAS E ESCOLAS DE GOVERNO, I., 2017, Florianópolis, SC. Anais do I SUCEG [...]. Florianópolis: [s. n.], 2017. p. 224-247.

APERIA, Anita et al. Competencies: A new currency for continuing professional development. Journal of Medicines Development Sciences, [S. l.], v. 3, n. 1, p. 1-7, 2017. BARDIN, Laurence. Análise de conteúdo. 6. ed. rev. e aum. São Paulo: Edições 70, 2011. 280 p. BITENCOURT, Claudia Cristina. A gestão de competências gerenciais e a contribuição da aprendizagem organizacional. Revista de Administração Eletrônica, [S. l.], v. 44, n. 1, p. 58-69, 2004.

CARBONE, Pedro Paulo et al. Gestão por competências e gestão do conhecimento. 3. ed. Rio de Janeiro: FGV, 2009. 176 p.

CARVALHO, Ana Carolina Vilela de; STEFANO, Silvio Roberto; MUNCK, Luciano. Competências voltadas à sustentabilidade organizacional: um estudo de caso em uma indústria exportadora. Gestão \& Regionalidade, [S. l.], v. 31, n. 91, p. 33-48, 2015. DOI 10.13037/gr.vol31n91.2278. 
CERIBELI, Harrison Bachion; ALMEIDA, Carolina Áurea Matos de. Gestão por competências: um estudo de caso em uma indústria no Brasil. Revista Globalização, Competitividade y Gobernabilidade, Boadilla del Monte, v. 9, n. 1, p. 118-130, 2015.

CERIBELI, Harrison Bachion et al. Gestão por competências: um estudo de caso em uma indústria de bebidas do Brasil. Nucleus, [S. l.], v. 16, n. 1, p. 1-14, 2019.

DERROSSO, Giuliano; BOEWERK, Samara. Gestão de desempenho por competência (GDP): análise da avaliação de desempenho utilizada em uma instituição bancária para ascensão profissional. Universitas Gestão e TI, Brasília, v. 7, n. 1-2, p. 1-16, 2017.

DUTRA, Carlos Antonio Furtado. A contribuição da gestão por competências para uma administração escolar participativa: um estudo de caso. Administração de Empresas em Revista, Curitiba, v. 17, n. 18, p. 68-82, 2017.

DUTRA, Joel Souza. Competências: conceitos, instrumentos e experiências. 2. ed. São Paulo: Atlas, 2017. $358 \mathrm{p}$.

ENKE, Judith et al. Advanced Engineering Education \& Training for Manufacturing Innovation. In: CONFERENCE ON LEARNING FACTORIES 2018, 8., 2018. Industrie 4.0 - Competencies for a modern production system [...] [S. l.]: Elsevier, 2018. p. 267-272.

GRAMIGNA, Maria Rita. Gestão por competências: ferramentas para avaliar e mapear perfis. Rio de Janeiro: Alta Books, 2017. 272 p.

GRZYBOWSKA, Katarzyna; LUPICKA, Anna. Key competencies for Industry 4.0. Economics and Management Innovations: Icemi 2017, [S. l.], p. 250-253, 2017.

LUDKE, M.; ANDRE, M. E. D. A. Pesquisa em educação: uma abordagem qualitativa. 2.ed. São Paulo: EpU, 2013.

MONTEIRO, Ana Claudia Fernandes; MOURÃO, Luciana. Desenvolvimento profissional: a produção científica nacional e estrangeira. Revista psicologia: organizações e trabalho, Brasilia, v. 17, n. 1, p. 39-45, 2017.

OLIVEIRA, Maxwell Ferreira de. Metodologia científica: um manual para a realização de pesquisas em administração. Catalão: UFG, 2011. 72 p.

PEREIRA, Adriana Soares et al. Metodologia da pesquisa científica. 1. ed. Santa Maria: Núcleo de Tecnologia Educacional, 2018. 118 p. E-book.

PIMENTEL, Alessandra. A teoria da aprendizagem experiencial como alicerce de estudos sobre desenvolvimento profissional. Estudos de psicologia, Natal, v. 12, n. 2, p. 159-168, 2007.

PRODANOV, Cleber Cristiano; FREITAS, Ernani Cesar de. Metodologia do trabalho científico: métodos e técnicas da pesquisa e do trabalho acadêmico. 2. ed. Novo Hamburgo: Feevale, 2013.

RUZZARIN, Ricardo; SIMIONOVSCHI, Marcelo. Competências: uma base para a governança corporativa. Porto Alegre: AGE, 2017. 198 p.

SCARPELLI, Renato Marcio; LIMA, Leandro Cearenço. Competências individuais: um estudo sobre a importância do indivíduo como diferencial competitivo nas organizações. Revista CONBRAD. v. 3, n. 3, p. 82-98, 2018.

SILVA, Andressa Hennig; FOSSÁ, Maria Ivete Trevisan. Análise de conteúdo: exemplo de aplicação da técnica para análise de dados qualitativos. Qualitas Revista Eletrônica, Campina Grande, v. 16, n. 1, p. 1-14, 2015.

SILVA, Vander Luiz da; KOVALESKI, João Luiz; PAGANI, Regina Negri. Competências bases para o trabalho humano na Indústria 4.0. Revista FOCO, [S. l.], v. 12, n. 2, p. 112-129, $2019 .$.

TREFF, Marcelo. Gestão de pessoas: olhar estratégico com foco em competências. 1. ed. Rio de Janeiro: Elsevier, 2016. 222 p.

TRIDAPALLI, Raquel Guedes. Gestão estratégica de pessoas: treinamento e desenvolvimento. Revista Maiêutica. v. 5, n. 1, p. 213-220, 2017.

YANAI, Angela Emi et al. "A Engenharia de Produção e as novas tecnologias produtivas: indústria 4.0, manufatura aditiva e outras abordagens avançadas de produção. In: ENCONTRO NACIONAL DE ENGENHARIA DE PRODUCAO, XXXVII., 2017, Joinville. O desenvolvimento da indústria 4.0: um estudo bibliométrico [...]. SC: 2017. 